\title{
Microwave-Assisted Protocol for Green Functionalization of Thiophenes With a Pd/ $\beta$-Cyclodextrin Cross-Linked Nanocatalyst
}

\section{Silvia Tabasso ${ }^{1}$, Emanuela Calcio Gaudino ${ }^{2}$, Elisa Acciardo ${ }^{2}$, Maela Manzoli ${ }^{2}$, Barbara Bonelli ${ }^{3}$ and Giancarlo Cravotto ${ }^{2 *}$}

${ }^{1}$ Dipartimento di Chimica, University of Turin, Turin, Italy, ${ }^{2}$ Dipartimento di Scienza e Tecnologia del Farmaco and NIS, Centre for Nanostructured Interfaces and Surfaces, University of Turin, Turin, Italy, ${ }^{3}$ Department of Applied Science and Technology, Politecnico di Torino, Turin, Italy

Microwaves (MW) are often the most efficient, in terms of heat exchange and conversion rate, of all the energy sources used to promote chemical reactions thanks to fast volumetric dielectric heating, and metal-catalyzed synthetic reactions under heterogeneous conditions are an eloquent example. We herein report a MW-assisted green protocol for the $\mathrm{C}-\mathrm{H}$ arylation of thiophenes with substituted aryl halides. This sustainable protocol carried out in $\gamma$-valerolactone (GVL) is catalyzed by Pd nanoparticles embedded in cross-linked $\beta$-cyclodextrin. In view of the excellent results achieved with activated substrates, the one-pot synthesis of a $4(3 H)$-quinazolinone derivative has been accomplished. A pressure-resistant MW reactor, equipped with multiple gas inlets, was used for sequential (i) $\mathrm{C}-\mathrm{H}$ arylation, (ii) reduction, and (iii) carbonylation in the presence of the same catalyst, but under different gas atmospheres. The robust heterogeneous Pd catalyst showed limited metal leaching in GVL, making this an efficient MW-assisted process with high atom economy.

Keywords: microwaves, heterogeneous catalysis, bio-based solvent, C-H arylation, fluorescent quinazolinone, one-pot synthesis

\section{INTRODUCTION}

With the growing concerns of environmental pollution and the depletion of natural resources, synthetic organic chemists are facing the challenge of designing "greener" methodologies (Sheldon, 2012). Effective heating is one of the key means with which to access desired chemical reactivity while ensuring suitable energy consumption. In this context, microwave (MW) dielectric heating is still today one of the most powerful tools for promoting synthetic transformations (De la Hoz and Loupy, 2012; Cravotto and Carnaroglio, 2017; Das et al., 2019).

MW not only significantly shorten reaction times and improve reaction yields and selectivity, but are also more environmentally friendly than traditional heating methods (Kappe, 2004; Moseley and Kappe, 2011). A broad array of new heterogeneous catalytic applications have been reported (Daştan et al., 2012; Cho et al., 2016) since Varma first introduced solid catalysts to MW-assisted organic synthesis (MAOS) (Polshettiwar and Varma, 2008; Polshettiwar et al., 2009). In addition to their recyclability, there are several other advantages to using solid catalysts in MAOS; heterogeneous catalysts are generally excellent MW absorbers, meaning that they provide a cooperative effect in MW-assisted reactions as the catalytic material is also the source of rapid internal heating (Kokel et al., 2017). 


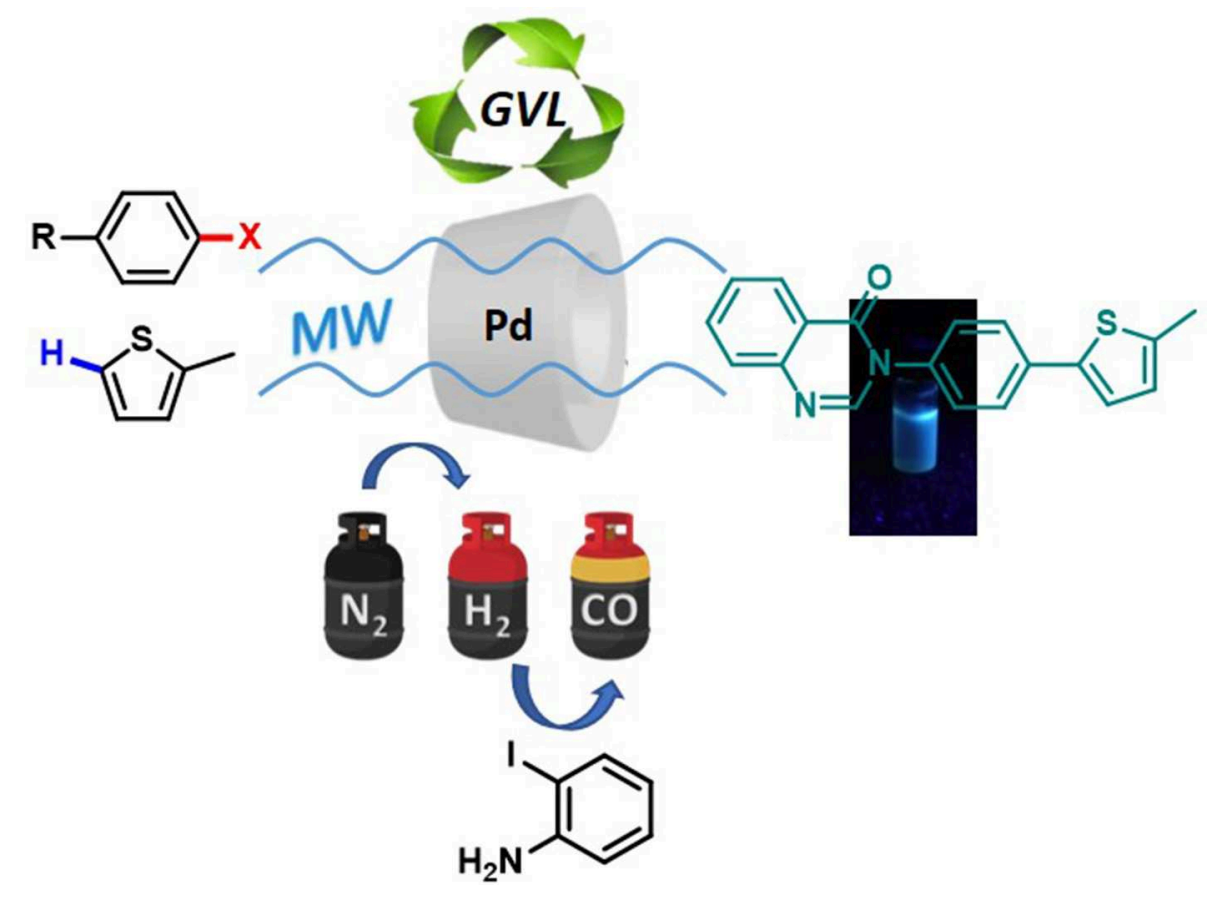

GRAPHICAL ABSTRACT | Microwaves-assisted protocol for green functionalization of thiophenes with Pd/ $\beta$-cyclodextrin cross-linked nanocatalyst.

The direct functionalization of otherwise inert $\mathrm{C}-\mathrm{H}$ bonds has recently emerged as a viable alternative (Gandeepan et al., 2019) to traditional cross-coupling reactions, and is a more sustainable approach to transition-metal-catalyzed organic reactions. This approach avoids the pre-functionalization of starting materials and makes $\mathrm{C}-\mathrm{H}$ activation even more appealing from the viewpoints of high atom and step economy, and high efficiency (Crabtree and Lei, 2017; Meyer et al., 2019).

Despite its many advantages, the development of this concept has also encountered significant challenges; $\mathrm{C}-\mathrm{H}$ activation processes often require high catalyst loadings (1-10 mol\%), (Turner et al., 2007) and phosphine ligands (Masui et al., 2004), and have been performed in toxic dipolar aprotic solvents. Furthermore, achieving regioselective $\mathrm{C}-\mathrm{H}$ activation is highly challenging as aromatic compounds typically contain multiple $\mathrm{C}-\mathrm{H}$ bonds. For this reason, the development of new methods for the sustainable synthesis of bi-heteroaryl scaffolds for use as the privileged $\pi$-conjugated cores of bioactive compounds, and as functional materials (Ackermann et al., 2009; Gandeepan et al., 2019) is an ongoing challenge for organic chemists. Although ligand-less protocols with low catalyst loadings have recently been developed by Doucet et al., the reaction is still hampered by its harsh conditions and the, up to, $20 \mathrm{~h}$ required for completion (Roger et al., 2009).

The use of heterogeneous reusable metal catalysts (Cano et al., 2015; Santoro et al., 2016; Warratz et al., 2017; Orduna et al., 2019), also in combination with MW irradiation technologies (Sharma et al., 2018), is a recent trend in the field of improving the sustainability of $\mathrm{C}-\mathrm{H}$ activation. However, the quest for less hazardous and more environmentally benign solvents is still of paramount importance for researchers that wish to perform transition-metal-catalyzed $\mathrm{C}-\mathrm{H}$ activation in an eco-friendly fashion (Fischmeister and Doucet, 2011; Jimenez-Gonzalez et al., 2011; Gutmann et al., 2015; Clarke et al., 2018; Santoro et al., 2018). To this end, alternative approaches for $\mathrm{C}-\mathrm{H}$ activation have been established, including "on water" (Kitanosono et al., 2018) and "solvent-free" (Martins et al., 2009), reaction conditions. In fact, biomass-derived solvents, such as PEGs, $\gamma$-valerolactone (GVL) and 2-methyltetrahydrofuran (MeTHF), have more recently been exploited for transition-metal-catalyzed $\mathrm{C}-\mathrm{H}$ activation reactions (Santoro et al., 2018). Bio-derived solvents display several advantages, including (i) availability from renewable feedstocks on scale, (ii) generally low toxicities, and (iii) high biodegradability, and may well be a suitable solution to the "solvent issue" in $\mathrm{C}-\mathrm{H}$ activation processes. In particular, GVL (Rasina et al., 2016), which is typically produced from the hydrogenation of lignocellulosic biomass-derived levulinic acid, has recently been used as a green reaction media for several transition-metal-catalyzed transformations (Tabasso et al., 2016). In particular, Ackermann and Vaccaro reported the first heterogeneous Pd-catalyzed Catellani reaction (Rasina et al., 2016) in GVL, and the same group also exploited the potential of GVL in the heterogeneous Pd-catalyzed direct arylation of 1,2,3-triazoles by aryl bromides (Tian et al., 2016). Although the above-mentioned use of GVL was performed under conventional heating, the interaction between GVL and microwaves has been 
recently investigated, with the media demonstrating stability and an ability to avoid the arching phenomena that frequently occurs in MW-assisted Pd/C-catalyzed (Petricci et al., 2018) reactions. These results pave the way for its use in MW-assisted heterogeneous catalysis.

In the context of combining MW irradiation and bio-derived reaction media, our laboratory has recently described the direct $\mathrm{C}-\mathrm{H}$ arylation of thiophenes in biomass-derived GVL under homogeneous catalysis (Tabasso et al., 2017). The ligand-free direct arylation of thiophenes was accomplished in GVL with very low Pd loading, leading to the MW-assisted synthesis of a poly(3-hexyl)thiophene (P3HT), and the role of GVL as a ligand in the catalytic system was also proven.

In the search for more sustainable approaches, we turned toward heterogeneous (Santoro et al., 2016) catalysis for C-H activation. We have recently developed a reusable heterogeneous catalytic system that is based on Pd that has been embedded into a cross-linked $\beta$-cyclodextrin $(\beta-C D)$ matrix (hereafter denoted as $\mathrm{Pd} / \mathrm{C} \beta \mathrm{CAT}$ system) (Cravotto et al., 2012; Calcio Gaudino et al., 2015, 2017), and obtained after the reticulation of $\beta$-CD with hexamethylene diisocyanate (HDI) in the presence of a $\operatorname{Pd}(\mathrm{II})$ salt solution (Tabasso et al., 2019). This heterogeneous catalyst has been used, in this work, for the MW-assisted C-H arylation of thiophenes in bio-derived GVL. Furthermore, we propose a one-pot synthesis of a $4(3 \mathrm{H})$-quinazolinone derivative via the reduction and carbonylation of the arylation product of 2-methylthiophene and bromonitrobenzene in GVL. A pressureresistant MW reactor that is equipped with multiple gas inlets has been used to facilitate the one pot synthesis of $4(3 \mathrm{H})$ quinazolinone in the presence of the same $\mathrm{Pd} / \mathrm{C} \beta \mathrm{CAT}$ catalyst under different gas atmospheres.

\section{EXPERIMENTAL SECTION}

All starting organic reagents and solvents were purchased from Sigma Aldrich and used without further purification. $\beta$-CD was purchased from Wacker Chemie, Munich, Germany.

The $\mathrm{Pd} / \mathrm{C} \beta C A T$ catalyst was prepared according to a previously reported procedure (Tabasso et al., 2019). The cross-linked $\mathrm{Pd} / \mathrm{C} \beta \mathrm{CAT}$ catalyst was obtained via sonochemical reticulation of $\beta-\mathrm{CD}$ with hexamethylene diisocyanate (HDI) in the presence of a $\mathrm{Pd}(\mathrm{II})$ salt solution. In particular, $\mathrm{Pd}(\mathrm{OAc})_{2}$ (200 mg, $0.89 \mathrm{mmol})$ and $\beta-\mathrm{CD}(1 \mathrm{~g}, 0.78 \mathrm{mmol})$ were dissolved in DMF ( $4 \mathrm{~mL}$ ) under sonication in a thermostated sonochemical reactor at room temperature. HDI $(2.8 \mathrm{~mL}, 17.4 \mathrm{mmol})$ was then added portionwise and the reaction mixture was kept under sonication at $60^{\circ} \mathrm{C}(21.1 \mathrm{kHz}, 60 \mathrm{~W})$ for $30 \mathrm{~min}$. The compact gel was crushed and washed with water $(100 \mathrm{~mL})$, acetone $(100 \mathrm{~mL})$, and methanol $(100 \mathrm{~mL})$. The product was filtered on a sintered glass Buchner funnel and dried overnight under vacuum at $75^{\circ} \mathrm{C}$, obtaining a brownish powder $(4.70 \mathrm{~g})$.

MW-assisted reactions were carried out in a SynthWAVE (MLS GmbH, Milestone Srl) reactor. The GC-MS analyses were performed in an Agilent 6890 system (Agilent Technologies, USA) fitted with a mass detector Agilent Network 5973 with a capillary column that was $30 \mathrm{~m}$ long, had an i.d. of $0.25 \mathrm{~mm}$ and a film thickness of $0.25 \mathrm{~mm}$. The GC conditions were: injection split of $1: 20$, injector temperature of $250^{\circ} \mathrm{C}$, and detector temperature of $280^{\circ} \mathrm{C}$. The gas carrier was helium $\left(1.2 \mathrm{~mL} \mathrm{~min}^{-1}\right)$, and the temperature program ran from $70^{\circ} \mathrm{C}$ (2 min) to $300^{\circ} \mathrm{C}$ at $5^{\circ} \mathrm{C} \mathrm{min}^{-1}$.

NMR spectra were recorded on a Jeol $600 \mathrm{ECZ} R$ at $25^{\circ} \mathrm{C}$ in $\mathrm{CDCl}_{3}$; chemical shifts were calculated relative to the residual solvent proton and carbon resonances.

Transmission electron microscopy (TEM) measurements were carried out using a side entry Jeol JEM $3010(300 \mathrm{kV})$ microscope, with a $\mathrm{LaB}_{6}$ filament, and fitted with X-ray EDS probe via a Link ISIS 200 detector. The samples, in the form of powders, were directly deposited onto a copper grid coated with a porous carbon film. Digital micrographs were acquired using an Ultrascan 1000 camera and processed using Gatan digital micrograph. The images were taken on several different regions of the grid and Pd particle-size distributions were built by counting a statistically representative number of particles (more than 200 particles). The mean particle diameter $\left(\mathrm{d}_{\mathrm{m}}\right)$ was calculated as follows: $\mathrm{d}_{\mathrm{m}}=\Sigma \mathrm{d}_{\mathrm{i}} \mathrm{n}_{\mathrm{i}} / \Sigma \mathrm{n}_{\mathrm{i}}$, where $\mathrm{n}_{\mathrm{i}}$ is the number of particles of diameter $\mathrm{d}_{\mathrm{i}}$. The analyses were firstly performed on the as-synthesized (fresh) catalyst. Other measurements were carried out on used $\mathrm{Pd} / \mathrm{C} \beta \mathrm{CAT}$, i.e., after the one-pot $4(3 H)$ quinazolinone synthesis reaction, and on the catalyst submitted to MW power at $200^{\circ} \mathrm{C}$.

XPS (X-ray Photoelectron Spectroscopy) analyses were carried out on XPS PHI 5000 Versa probe apparatus using a band-pass energy of $187.85 \mathrm{eV}$, a $45^{\circ}$ take-off angle and a $100.0 \mu \mathrm{m}$ diameter X-ray spot size for survey spectra. Highresolution XP spectra were recorded under the following conditions: pass energy of $20 \mathrm{eV}$, resolution of $0.1 \mathrm{eV}$ and step of $0.2 \mathrm{eV}$. Sample charging effects were eliminated by referring to the spectral line shift of the $\mathrm{C} 1 \mathrm{~s}$ binding energy (BE) value at $284.5 \mathrm{eV}$. XP-spectra were analysed using commercial software (CasaXPS, version 2.3.16), and applying mixed GaussianLorentzian (70-30\%) profiles.

\section{General Procedure for Direct Arylation of Thiophenes}

The aryl halide $(0.5 \mathrm{mmol})$, thiophene derivative $(1 \mathrm{mmol})$, $\mathrm{KOAc}(1 \mathrm{mmol})$, and $\mathrm{PivOH}(0.15 \mathrm{mmol})$ were placed into a quartz vial equipped with a magnetic stirrer and suspended in GVL $(3 \mathrm{~mL})$. The vial was purged with $\mathrm{N}_{2}$ and $\mathrm{Pd} / \mathrm{C} \beta C A T$ $(0.2 \mathrm{~mol} \%)$ was added. The mixture was heated to the required temperature under MW irradiation for $2 \mathrm{~h}$ in a $\mathrm{N}_{2}(1 \mathrm{MPa})$ atmosphere under magnetic stirring $(450 \mathrm{rpm})$. The reactor was cooled after $2 \mathrm{~h}$ and the crude reaction was filtered to recover the catalyst. Water $(4 \mathrm{~mL})$ was added to the filtrate and the solid products were recovered via precipitation, filtered off and washed with $1 \mathrm{~mL}$ of cold water. The solid was then dried under vacuum and purified by flash column chromatography (hexane). Alternatively, liquid products were extracted using $3 \mathrm{~mL}$ EtOAc and purified by flash column chromatography (hexane) after solvent evaporation.

\section{One-Pot Synthesis of 4(3H) Quinazolinone Derivative}

The aryl bromide $2 \mathrm{a}(0.5 \mathrm{mmol})$, 2-methylthiophene 1a (1 $\mathrm{mmol}), \mathrm{KOAc}(1 \mathrm{mmol})$ and $\mathrm{PivOH}(0.15 \mathrm{mmol})$ were placed into a quartz vial equipped with a magnetic stirrer and suspended 


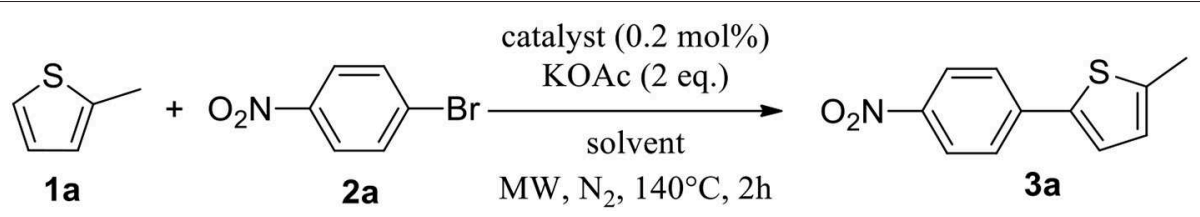

SCHEME 1 | C-H direct arylation of 2-methythiophene with 4-bromonitrobenezene.

TABLE 1 | MW-assisted C-H direct arylation of 2-methythiophene with 4-bromonitrobenezene.

\begin{tabular}{llllc}
\hline Entry & Ligand & Catalyst & Solvent & Yield $^{\mathbf{a}}$ (\%) \\
\hline 1 & - & $\mathrm{Pd}(\mathrm{OAc})_{2}$ & $\mathrm{DMAc}$ & 100 \\
2 & - & $\mathrm{Pd} / \mathrm{C} \beta \mathrm{CAT}$ & $\mathrm{DMAc}$ & 100 \\
3 & - & $\mathrm{Pd}(\mathrm{OAC})_{2}$ & $\mathrm{GVL}$ & 73 \\
4 & & $\mathrm{Pd} / \mathrm{C} \beta \mathrm{CAT}$ & $\mathrm{GVL}$ & $78(81)^{\mathrm{b}}$ \\
$5^{\mathrm{c}}$ & - & $\mathrm{Pd} / \mathrm{C} \beta \mathrm{CAT}$ & $\mathrm{GVL}$ & 51 \\
$6^{\mathrm{d}}$ & - & $\mathrm{Pd} / \mathrm{C} \beta \mathrm{CAT}$ & $\mathrm{GVL}$ & 42 \\
$7^{\mathrm{e}}$ & - & $\mathrm{Pd} / \mathrm{C} \beta \mathrm{CAT}$ & $\mathrm{GVL}$ & 36 \\
7 & $\mathrm{PivOH}(0.3$ eq. $)$ & $\mathrm{Pd}(\mathrm{OAC})_{2}$ & $\mathrm{GVL}$ & 82 \\
8 & $\mathrm{PivOH}(0.3$ eq. $)$ & $\mathrm{Pd} / \mathrm{C} \beta \mathrm{CAT}$ & $\mathrm{GVL}$ & 100 \\
\hline
\end{tabular}

a Yields as determined by GC; ${ }^{b} 140^{\circ} \mathrm{C}, 4 h^{c}{ }^{c} 160^{\circ} \mathrm{C}, 2 h^{d} 180^{\circ} \mathrm{C}, 2 \mathrm{~h}$; ${ }^{e} 200^{\circ} \mathrm{C}, 2 \mathrm{~h}$.

in GVL ( $3 \mathrm{~mL})$. The vial was purged with $\mathrm{N}_{2}$ and Pd/CßCAT $(0.2$ mol\%) was added. The mixture was heated to $140^{\circ} \mathrm{C}$ under $\mathrm{MW}$ irradiation (average power $960 \mathrm{~W}$ ) in a $\mathrm{N}_{2}(1 \mathrm{MPa})$ atmosphere under magnetic stirring (450 rpm). After $2 \mathrm{~h}, \mathrm{H}_{2}$ (15 bar) was flushed into the reaction mixture for $15 \mathrm{~min}$, and the temperature was increased to $160^{\circ} \mathrm{C}$. The residual internal pressure was carefully released after the reaction chamber was cooled to $35^{\circ} \mathrm{C}$. O-iodoaniline $(0.5 \mathrm{mmol})$ and trimethyl orthoformate $(0.6$ $\mathrm{mmol}$ ) were added and $\mathrm{CO}$ pressure ( 5 bar) was loaded at room temperature. The mixture was heated at $145^{\circ} \mathrm{C}$ for $4 \mathrm{~h}$ under magnetic stirring. After the reaction chamber was cooled, the Pd catalyst was filtered off on a sintered-glass Buchner funnel and washed twice with GVL. Water $(3 \mathrm{~mL})$ was then added to the filtrate solution, and the product was recovered after precipitation, filtered off and washed with $1 \mathrm{~mL}$ of cold water. The obtained precipitate was filtered off, washed twice with water, and finally dried under vacuum. Product purification was performed via flash-chromatography (petroleum ether 40-60/EtOAc $=7: 3$ $\mathrm{v} / \mathrm{v})$, yielding the $4(3 \mathrm{H})$-quinazolinone derivative (6).

\section{RESULTS AND DISCUSSION \\ Direct Arylation of Thiophenes}

The polar nature of cyclodextrins makes them good candidates for interaction with MW, meaning that they are therefore particularly efficient at adsorbing the irradiation. For this reason, they can be used as supports for metals (Hapiot et al., 2014) in MW-assisted reactions (Cintas et al., 2012; Cravotto et al., 2012). In addition, the structural features of aromatic compounds mean that they fit the cyclodextrin cavity well (Connors, 1997).
In a previous work, we described the ligand free $\mathrm{C}-\mathrm{H}$ arylation of thiophenes in GVL (Tabasso et al., 2017) using $\mathrm{Pd}(\mathrm{OAc})_{2}$ as the catalyst and potassium acetate (KOAc) as the base. Herein, we explore the same reaction, under the previously optimized conditions, but using a heterogeneous $\mathrm{Pd} /$ cross-linked $\beta-\mathrm{CD}$ catalyst $(\mathrm{Pd} / \mathrm{C} \beta \mathrm{CAT})$, both to improve the sustainability of the process and to investigate the active catalytic species that are formed under the $\mathrm{MW}$-assisted reaction. The direct $\mathrm{C}-\mathrm{H}$ arylation between 2-methylthiophene and 4-bromonitrobenzene (Scheme 1) was investigated, as the first phase, and the Pd/crosslinked $\beta$-CD catalyst was compared to $\mathrm{Pd}(\mathrm{OAc})_{2}$ (Table 1). The metal content in the homogeneous and heterogeneous catalysis reactions was the same $(0.2 \mathrm{~mol} \%)$. The green solvent, GVL, was also compared to dimethylacetamide (DMAc), one of the most commonly used conventional dipolar aprotic solvents.

$\mathrm{Pd} / \mathrm{C} \beta \mathrm{CAT}$ showed itself to be a valuable alternative to homogeneous catalysis when used in conventional solvents, as shown in Table 1, entry 2. However, the product yield was lower in GVL, as reagent conversion did not complete, even when the reaction time was prolonged to $4 \mathrm{~h}$ (Table 1 , entry $4 \mathrm{~b}$ ) and when the temperature was raised (Table 1, entry 5, 6, and 7). As described more in detail in Paragraph 2.3 and in the Supplementary Material, the increase of MW power at temperatures higher than $140^{\circ} \mathrm{C}$ causes a higher MW adsorption by cross-linked CD structures, that negatively affect its stability, as confirmed by TEM analysis (Figures $\mathbf{3 b}, \mathbf{c}$ ). Aiming to promote the reaction, we added $\mathrm{PivOH}$ as a ligand (in the form of pivalate, Lafrance and Fagnou, 2006). This improvement resulted in complete conversion to the product (Table 1, entry 8). It is worth noting that the heterogeneous catalyst was more efficient than $\mathrm{Pd}(\mathrm{OAc})_{2}$ when used in GVL. This may be due to the higher stability of the active Pd species in the catalyst network, thus avoiding the formation of Pd black, as will be discussed below (section Effect of Microwaves on the $\mathrm{Pd} / \beta-\mathrm{CD}$ CrossLinked Nanocatalyst). Indeed, as $\operatorname{Pd}(0)$ is the catalytically active species, metal aggregation (and catalyst deactivation) can occur when using $\mathrm{Pd}(\mathrm{OAc})_{2}$, as GVL is less efficient than DMAc in coordinating Pd atoms (Tabasso et al., 2017). The optimized conditions were then applied to other substrates and the action of the two catalysts $\mathrm{Pd}(\mathrm{OAc})_{2}$ and $\mathrm{Pd} / \mathrm{C} \beta \mathrm{CAT}$ was compared (Table 2).

It was observed that MW significantly promoted the reaction, and the same reaction gave much lower yields under conventional heating (Table 2, entry 23 and Table S1). In particular, the complete conversion of the substrate took longer without MW irradiation; the compounds detected in the reaction mixture were mainly the reagents. Electron-deficient aryl halides, 
TABLE 2 | MW-assisted coupling of heteroaromatics and aryl halides.

Entry Heteroaryl
2
$1 \mathrm{~b}$<smiles>CCCCc1ccc(-c2ccc([N+](=O)[O-])cc2)s1</smiles>
$3 \mathbf{b}$

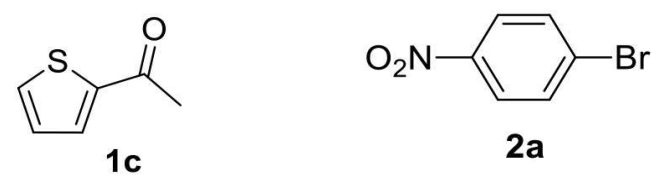

$2 \mathbf{a}$

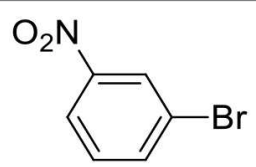

$2 \mathbf{b}$

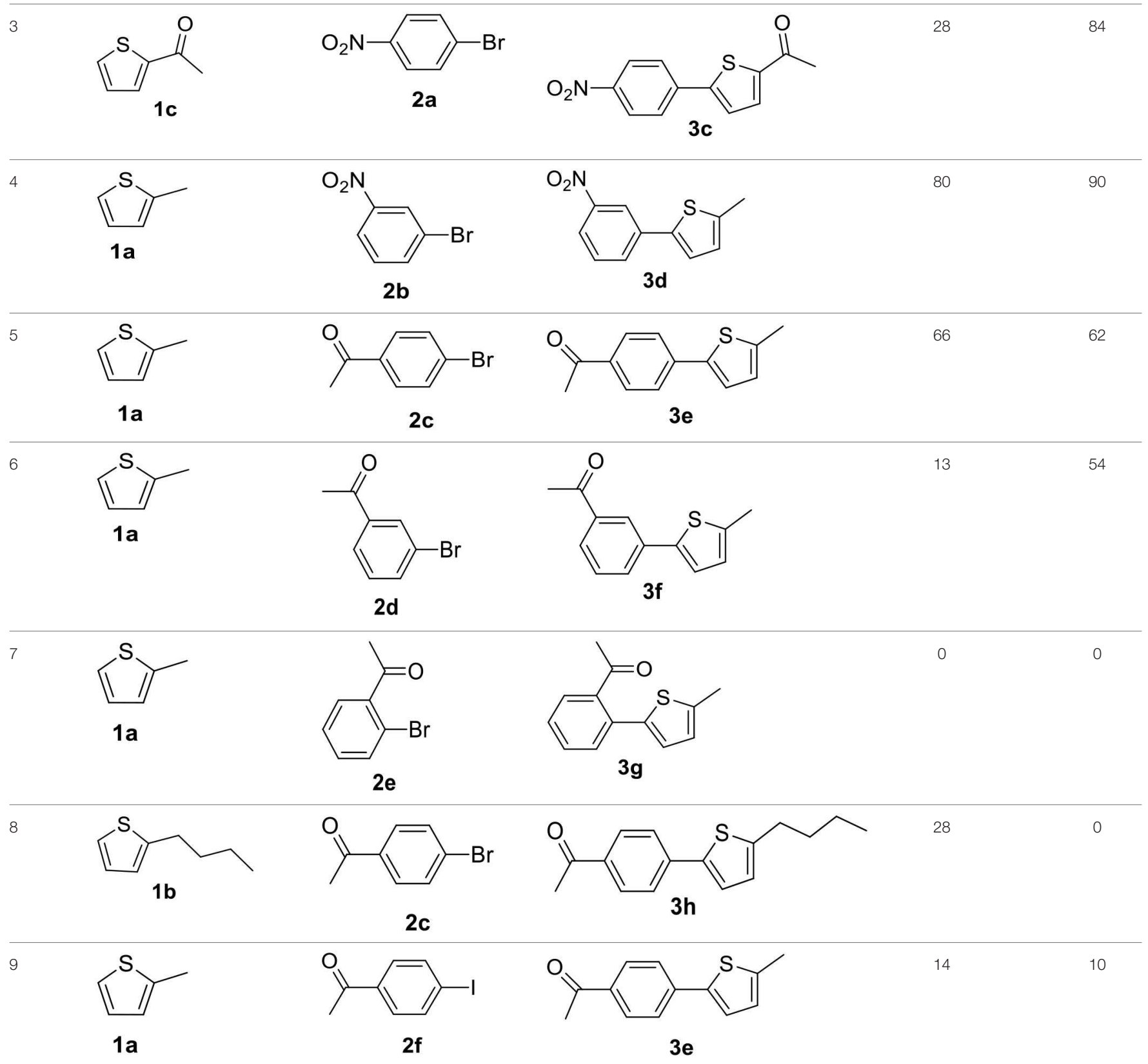


TABLE 2 | Continued

\begin{tabular}{|c|c|c|c|c|c|}
\hline Entry & Heteroaryl & Aryl halide & Product & $\begin{array}{l}\text { Yield (\%) } \\
\text { Pd(OAc) }\end{array}$ & $\begin{array}{l}\text { Yield }(\%)^{a} \\
\text { Pd/C } \beta C A T\end{array}$ \\
\hline $10^{\mathrm{b}}$ & $1 a$ & $2 g$ & $3 i$ & 0 & 0 \\
\hline 11 & $1 a$ & $2 h$ & 31 & 90 & 93 \\
\hline 12 & C & h & $3 m$ & 86 & 74 \\
\hline
\end{tabular}

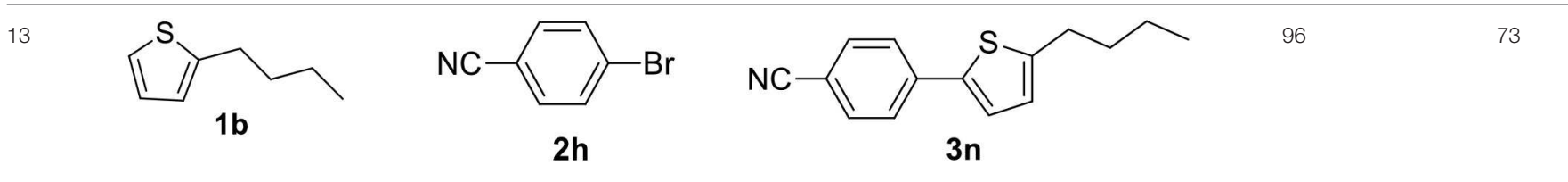

(1)
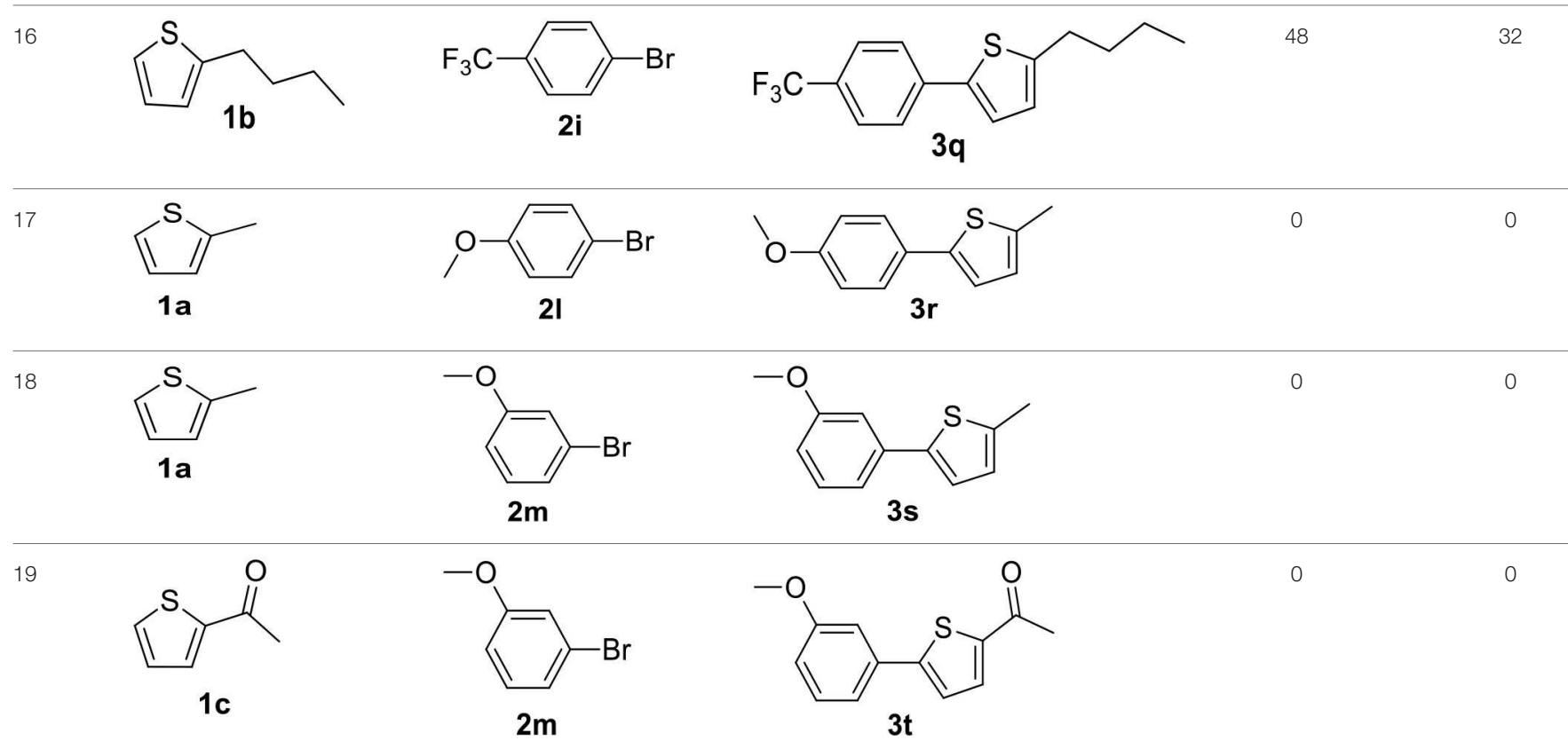
TABLE 2 | Continued

\begin{tabular}{|c|c|c|c|c|c|}
\hline Entry & Heteroaryl & Aryl halide & Product & $\begin{array}{l}\text { Yield (\%) } \\
\text { Pd(OAc) }\end{array}$ & $\begin{array}{l}\text { Yield (\%) } \\
\text { Pd/C } \beta C A T\end{array}$ \\
\hline 20 & $1 a$ & $2 n$ & $3 r$ & 42 & 24 \\
\hline 22 & $1 \mathrm{a}$ & & & 52 & 19 \\
\hline $23^{c}$ & & & & 2 & 3 \\
\hline
\end{tabular}

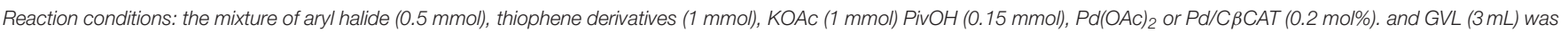
heated to $140^{\circ} \mathrm{C}$ under MW irradiation for $2 \mathrm{~h}$.

a Yields as determined by GC.

${ }^{b}$ Reaction performed at $200^{\circ} \mathrm{C}$.

${ }^{c}$ Conventional heating.

such as 1-bromo-4-nitrobenzene and 1-bromo-3-nitro benzene, react smoothly with thiophenes (Table 2, entries 1-4). Quite surprisingly, the heterogeneous catalyst had a much stronger effect on the reaction of 2-acetylthiophene (Table 2, entry 3) than $\mathrm{Pd}(\mathrm{OAc})_{2}$. This may be due to the cyclodextrins being highly responsive to $\mathrm{MW}$ irradiation, leading to the rapid heating of the catalytic site. In some cases, the higher yields obtained using Pd/C $\beta C A T$ can be ascribed to the tridimensional substrate structures having a good fit within the catalyst framework, such as in the coupling of 3-bromoacetophenone and methylthiophene (Table 2, entry 6). On the other hand, heterogeneous reaction yields were often lower than the homogeneous reactions when using n-butylthiophene as a reagent (Table 2, entries 8, 13, 16, 21). These results may be caused by the n-alkyl moiety's strong binding to cyclodextrins (expressed by $\mathrm{pKd}=-\log \mathrm{K}$ ), which increases monotonically with alkyl chain length, up to about eight carbons (Tee et al., 1996); the higher stability of the $n$ butylthiophene-cyclodextrin complex means that the reaction proceeds more slowly.

The attempt to couple deactivated aryl halides and thiophene was quite disappointing as only aryl iodides led to the desired products in the presence of the methoxy group (Table 2, entries $20,21,22$ ), and the homogeneous catalyst gave higher yields.

The reusability of the catalyst was investigated by repeating the optimized reaction procedure between 2-methythiophene and 4-bromonitrobenezene with a used catalyst, after washing it with water, methanol and acetone. After the first Pd/C $\beta C A T$ recycle the product yield remains high (90\%) with a negligible metal leaching $(0.98 \%)$ as confirmed by ICP-OES. However, the comparison between the XRD patterns of the as synthesized and recycled catalyst (Figure S4) revealed the formation of some peaks possibly ascribed to the $\mathrm{PdS}_{2}$ crystal phase (JCPDS file number 00-011-0497) along with the presence of peaks related to cubic Pd (JCPDS file number 00-001-1201). The broad peaks related to $\beta$-CD crosslinked with HDI moieties do not significantly change after recycling. However, the formation of the S-containing Pd species can poison the catalyst.

\section{Synthesis of a $4(3 H)$-Quinazolinone Derivative}

These encouraging results, especially with activated substrates, drove us to apply this process to the synthesis of a $4(3 H)$ quinazolinone derivative. These compounds have been widely explored because of the broad scope of their beneficial biological activities (Cao et al., 2005; Khan et al., 2016). A great deal of effort has been invested in the development of easy-to-handle, cost-effective and eco-friendly protocols for their preparation. An environmentally sustainable synthesis for $4(3 H)$-quinazolinone moieties that proceeds via MW-assisted 

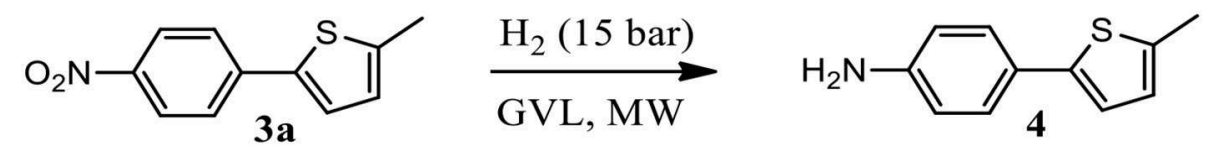

SCHEME 2 | Optimized conditions for the MW-assisted reduction step.

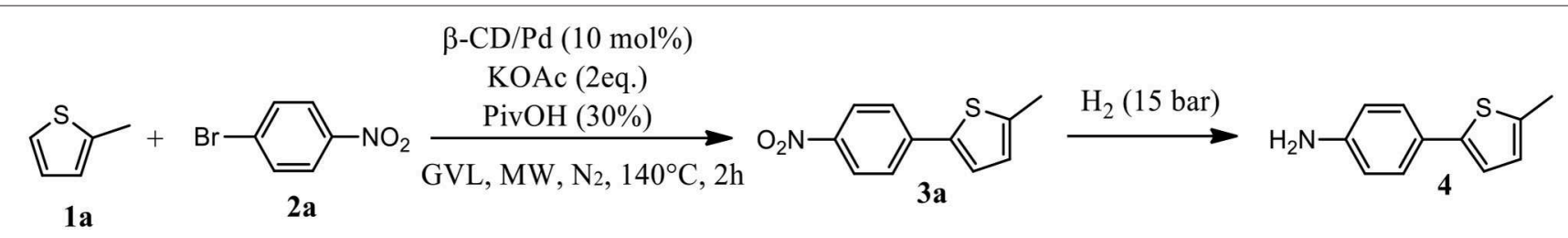

SCHEME 3 | Sequential direct arylation and reduction reactions.

TABLE 3 | Optimization of the second step of the one-pot synthesis of 2-methyl-5-(4-aminophenyl)thiophene.

\begin{tabular}{lccc}
\hline Entry & $\mathbf{T}\left({ }^{\circ} \mathbf{C}\right)$ & Time & Yield (\%) $^{\mathbf{a}}$ \\
\hline 1 & 120 & $15^{\prime}$ & 9 \\
2 & 160 & $15^{\prime}$ & 100 \\
3 & 160 & $5^{\prime}$ & 11 \\
\hline
\end{tabular}

a Yields as determined by GC.

carbonylative reactions in GVL has recently been published (Calcio Gaudino et al., 2017).

The first step of this process, the MW-assisted reduction of 2-methyl-5-(4-nitrophenyl)thiophene (Scheme 2), was therefore optimized in GVL. However, the product yield was not satisfactory (25\%) when working with $0.2 \%$ of $\mathrm{Pd}$. We therefore decided to use a higher amount of catalyst (10\% mol Pd), as has recently been described for reduction reactions under MW dielectric heating, and product $\mathbf{4}$ was obtained in a quantitative yield in only $15 \mathrm{~min}$ at $120^{\circ} \mathrm{C}$.

However, it was necessary to increase the temperature to $160^{\circ} \mathrm{C}$ to achieve complete conversion to desired product 4 (Scheme 3) when performing the one-pot reaction between 2methythiophene and 4-nitrobenzene (Table 3, entry 2). Reaction times could not be reduced any further with this temperature increase (Table 3, entry 3 ).

The synthesis of the $4(3 \mathrm{H})$-quinazolinone derivative was then accomplished via a carbonylative coupling of 2-methyl5-(4-aminophenyl)thiophene with $o$-iodoaniline, according to a previously reported procedure (Calcio Gaudino et al., 2017), using trimethyl orthoformate under CO pressure (Scheme 4). We have compared the previously used base, triethylamine (TEA), with KOAc, which is the base used in the C-H activation step. As shown in Table 4, increasing the time, temperature and $\mathrm{CO}$ pressure led to higher product yields being achieved using KOAc (entry 3 ) than with TEA (entry 4).

The optimized conditions for each step were applied to a onepot synthesis, which was made possible by the multiple gas inlets of the MW reactor that allow different reactive gas atmospheres to be used in sequence. Sequential C-H arylation, reduction and carbonylative coupling reactions were therefore performed in GVL using the same heterogeneous catalyst, and KOAc as the base (Scheme 5). Although higher Pd content (10\% mol) was used for the synthesis of the $4(3 \mathrm{H})$-quinazolinone derivative, metal leaching, as determined by ICP-OES, was observed to be very low after the one-pot reaction (1.04\%). This is due to both the polymer network of the catalyst and the solvent, as GVL is known to be an optimal medium for limiting Pd leaching.

The newly synthesized quinazolinone derivative $\mathbf{6}$ showed interesting fluorescence properties and a solvatochromic effect when illuminated with ultraviolet light (Figure 1).

$4(3 \mathrm{H})$-quinazolinone derivatives are not so well-known for their luminescent properties, whereas thiophenebased materials have undergone extensive investigations into their emissive applications (Rasmussen et al., 2015). Nevertheless, the fluorescence properties of potentially bioactive compounds, for example, antiviral, antimalarial and anticancer agents, may potentially permit the highly useful in-vitro monitoring of compound-treated cultured cells by fluorescence microscopy. 4(3H)-quinazolinone derivative $\mathbf{6}$ showed promising fluorescence intensity when excited at $300 \mathrm{~nm}$ (Figures S1a,b).

\section{Effect of Microwaves on the $P d / \beta-C D$ Cross-Linked Nanocatalyst}

TEM combined with EDS measurements and XPS analyses were carried out on the as-synthesized (fresh) and used, i.e., after the one-pot 4(3H)-quinazolinone synthesis reaction, catalyst to investigate the effect of MW on the morphology, $\mathrm{Pd}$ dispersion and nature of the species exposed on the surface of $\mathrm{Pd} / \mathrm{C} \beta \mathrm{CAT}$. It is worth noting that both fresh and used $\mathrm{Pd} / \mathrm{C} \beta \mathrm{CAT}$ catalysts were found to be stable to prolonged exposure to the electron beam of the instrument, in terms of Pd nanoparticle size and morphology (no metal coalescence), during the TEM measurements. Analogously, the cross-linked $\beta$ cyclodextrin support also showed no modifications, proving the intrinsic stability of the framework. 
Pd nanoparticles with a roundish shape were observed on the fresh catalyst (Figure 2a). A significant fraction of these had sizes between 2 and $4 \mathrm{~nm}$, giving a mean diameter of 3.4 $\pm 0.8 \mathrm{~nm}$ (Figure $\mathbf{2 b}$ ), which highlights the stabilization of the nanoparticles by the support. Moreover, XPS analyses revealed that the surface atomic percentages of $\mathrm{Pd}$ (at. \% Pd) were 0.3 and 0.2 , in the fresh and used samples, respectively, which correspond to ca. 2.3 (fresh sample) and 1.6 (used sample) wt. $\% \mathrm{Pd}$. This demonstrates that some leaching occurred during the $\mathrm{MW}$-assisted reaction, as revealed by ICP.

The XP spectra in the binding-energy $(\mathrm{BE})$ range of the $\mathrm{Pd}$ $3 \mathrm{~d}$ line are reported in Figure 2. The fresh-sample spectrum (Figure 2c), in particular, was extremely noisy and no reliable curve-fitting procedure could be performed; a broad, weak

TABLE 4 | Optimization of the conditions for the carbonylative coupling reaction.

\begin{tabular}{|c|c|c|c|c|c|}
\hline Entry & Base & co (bar) & $\mathrm{T}\left({ }^{\circ} \mathrm{C}\right)$ & Time (h) & Yield $^{\mathrm{a}}(\%)$ \\
\hline 1 & $\mathrm{KOAC}$ & 2.5 & 125 & 1 & - \\
\hline 2 & TEA & 7.5 & 125 & 3 & 30 \\
\hline 3 & KOAC & 5 & 145 & 4 & 88 \\
\hline 4 & TEA & 5 & 145 & 4 & 60 \\
\hline
\end{tabular}

a Yields as determined by GC. signal (dots) was observed, and the red line is an interpolated curve with two maxima at ca. 396.9 and $341.4 \mathrm{eV}$, i.e., at $\mathrm{BE}$ values that are in agreement with the presence of $\mathrm{Pd}^{2+}$ species, as is expected considering the synthesis procedure adopted. The XP spectrum, recorded after Ar sputtering (not reported), with the aim of improving the signal-to-noise ratio, was not reliable, as the sputtering procedure probably modified

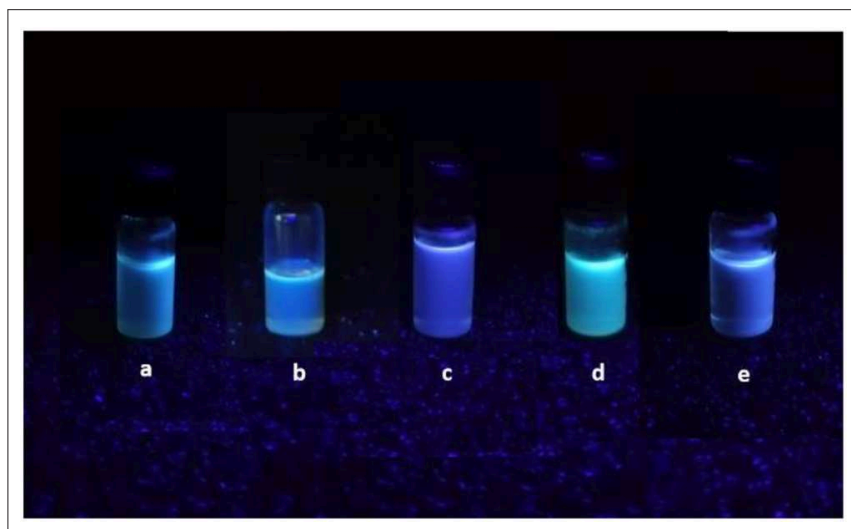

FIGURE 1 | Quinazolinone 6 fluorescence: (a) $\mathrm{CH}_{3} \mathrm{CN}$, (b) $\mathrm{CH}_{2} \mathrm{Cl}_{2}$, (c) EtOAc, (d) $\mathrm{MeOH}$, (e) acetone.
$\mathrm{CO}$

$\beta-\mathrm{CD} / \mathrm{Pd} 10 \%$

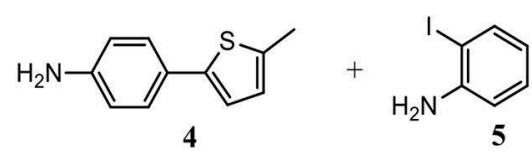

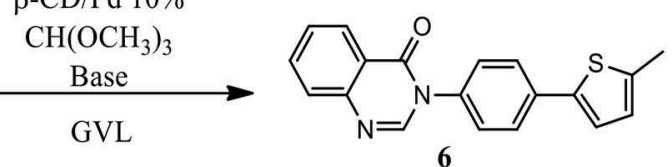

SCHEME 4 | Carbonylative coupling reaction.

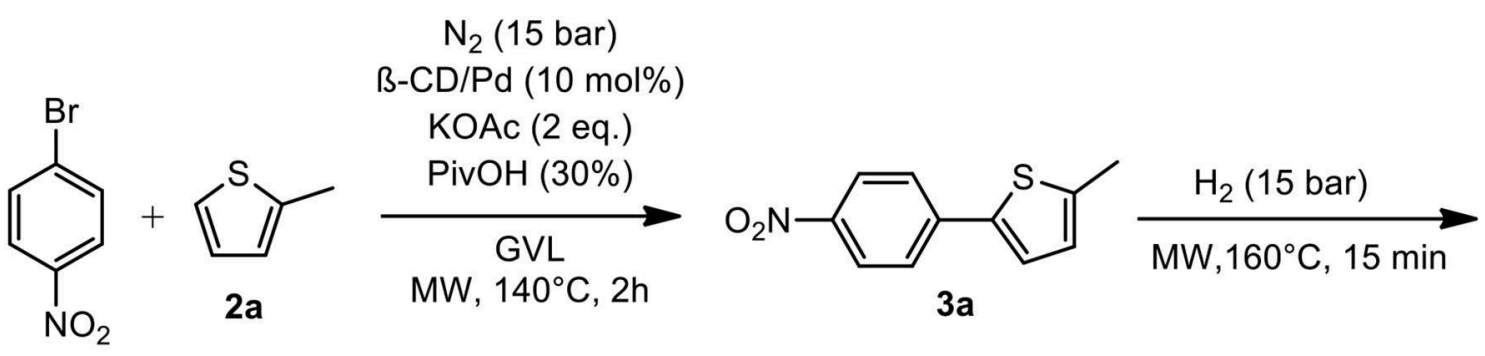

1 a
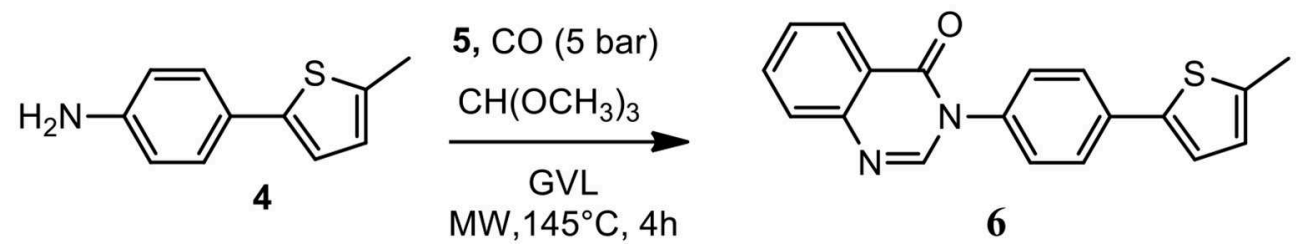

6

SCHEME 5 | One-pot synthesis of the $4(3 H)$-quinazolinone derivative. 

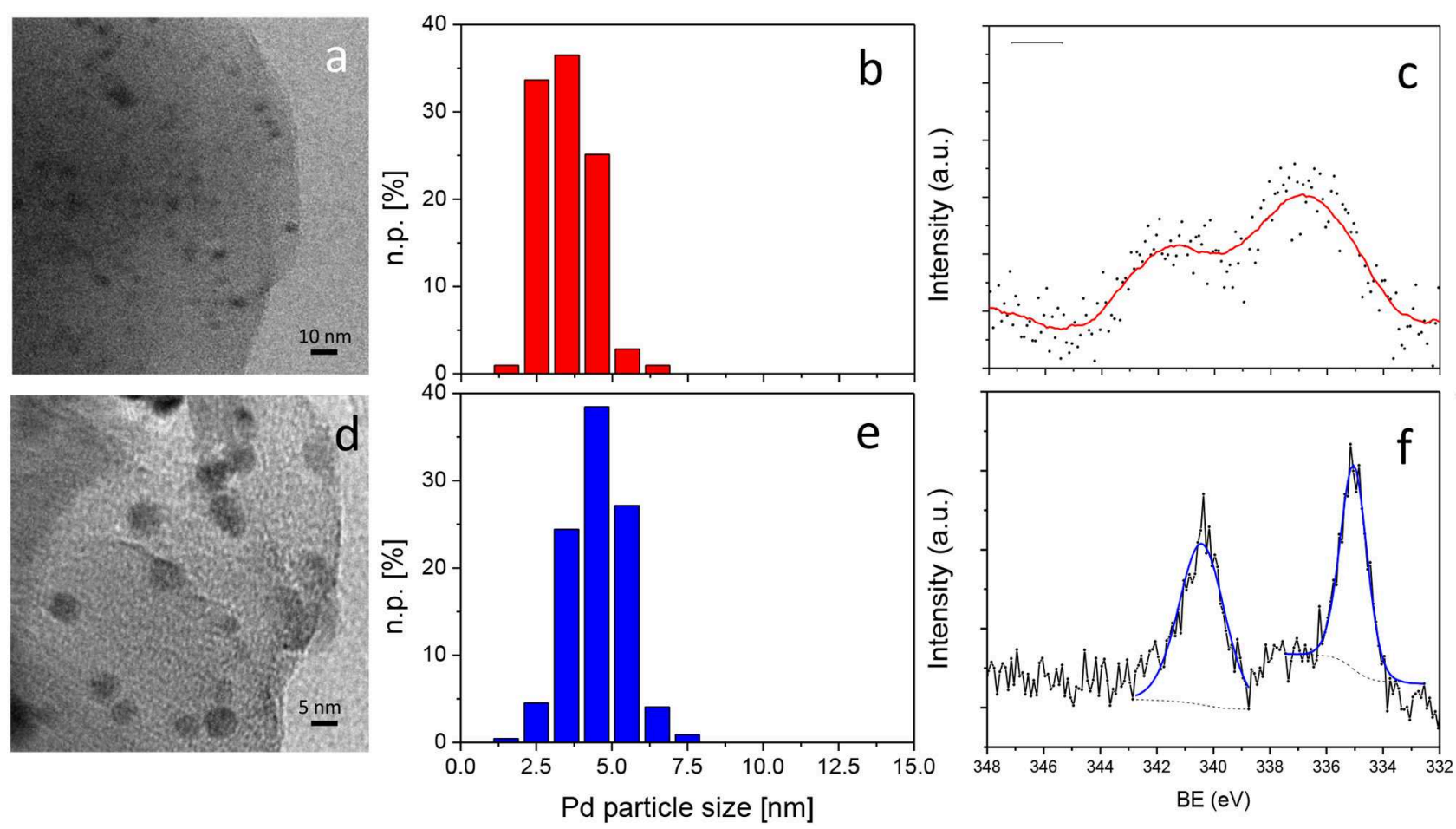

FIGURE 2 | TEM representative images of (a) fresh Pd/C $\beta C A T$ and (d) Pd/C $\beta C A T$ after the one-pot 4(3H)-quinazolinone synthesis reaction. Corresponding Pd particle-size distributions (b,e, respectively). Instrumental magnification: 150,000 $\times$ and 300,000x, respectively. n.p. [\%] = number of counted particles of diameter di XP-spectra of the fresh (c) and used (f) samples in the Pd 3d line range. Section (c) the red curve is obtained from the interpolation of the XPS signal. Section (f) the blue curve is the result of the curve-fitting procedure and the dotted line is the background.

\begin{tabular}{ccc}
\hline \multirow{2}{*}{$\begin{array}{c}\text { Reaction } \\
\text { Temperature }\left({ }^{\circ} \mathbf{C}\right)^{\mathbf{a}}\end{array}$} & Applied MW & Power (Watt) \\
\cline { 2 - 3 } & ramp (5 min) & average (2 h) \\
\hline 140 & 946 & 464 \\
160 & 1114 & 709 \\
180 & 1106 & 727 \\
200 & 1051 & 776 \\
\hline
\end{tabular}

${ }^{\text {a }} \mathrm{MW}$ assisted C-H direct arylation of 2-methythiophene (1 $\mathrm{mmol})$ with 4-bromonitrobenezene $(0.5 \mathrm{mmol})$ in presence of $\mathrm{KOAc}(1 \mathrm{mmol}), \mathrm{Pd} / \mathrm{C} \beta \mathrm{CAT}(0.2 \mathrm{~mol} \%)$ and GVL $(3 \mathrm{~mL})$.
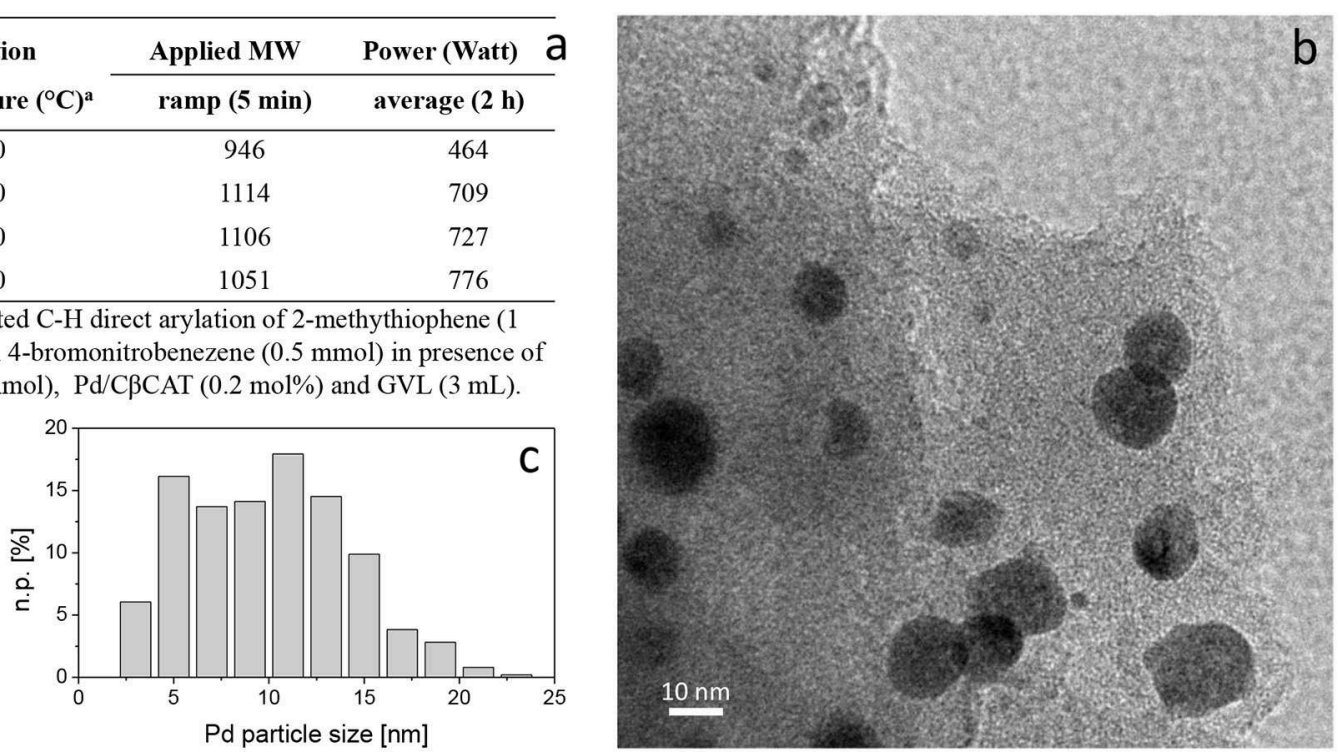

FIGURE 3 | MW-assisted C-H direct arylation: influence of MW power on Pd/C $\beta C A T$ stability (a). TEM representative image of Pd/C $\beta C A T$ under average power of $776 \mathrm{~W}$ at $200^{\circ} \mathrm{C}$ (b), and corresponding Pd particle-size distribution (c). Instrumental magnification: $150000 \times$, n.p. [\%] = number of counted particles of diameter di .

the sample surface. Indeed, XPS analyses of Pd-containing samples is often complicated by $\mathrm{PdO}$ reacting with $\mathrm{X}$-rays, when it is present, and the fact that Pd nanoparticles, when present, are often quickly oxidized upon the sample's exposure to air, usually forming core-shell Pd-PdO nanoparticles (Voogt et al., 1996). 
The Pd nanoparticles showed contained agglomeration upon the MW-assisted process; a mean diameter of $4.5 \pm 1.2 \mathrm{~nm}$ was estimated and the particle-size distribution appeared to be shifted toward sizes of 4-5 $\mathrm{nm}$ (Figure 2e).

Both the EDS analyses and XPS revealed the presence of S (1.31 and 0.95 wt. \%, respectively) at the surface of used $\mathrm{Pd} / \mathrm{C} \beta C A T$ (see also Figure S3). This is most likely due to the adsorption of some of the reaction products (seeing as complete conversion was observed during the reaction, the presence of unreacted species can be reasonably ruled out) that were not removed by washing.

Differently from what obtained for the fresh catalyst, the XP spectrum of the used sample, in the Pd $3 d$ range, (Figure 2f) was curve-fitted with a single component, with maxima at $335.05 \mathrm{eV}$ (Pd 3d 5/2) and 340.45 eV (Pd 3d 3/2), with a splitting of $5.40 \mathrm{eV}$. The observed shift and splitting are in agreement with literature values reported for $\mathrm{Pd}^{0}$, as the $\mathrm{Pd} 3 \mathrm{~d} 5 / 2$ line of bulk $\mathrm{Pd}^{0}$ is found at $335.1 \mathrm{eV}$, with a separation of $c a$. $+5.3 \mathrm{eV}$ from the $\mathrm{Pd} 3 \mathrm{~d} 3 / 2$ (Rao et al., 2017).

Aiming to investigate the influence of MW power on the stability of metallic nanoparticles and catalytic activity, tests at higher temperatures $\left(160,180\right.$, and $200^{\circ} \mathrm{C}$, Table 1, entries 5, 6 and 7) were performed. Figure 3a reports the applied MW power ( $5 \mathrm{~min}$ ramp and $2 \mathrm{~h}$ average power) on a reaction carried out at different temperatures. Moreover, the power variation with temperature is reported in Graphs S1a-d.

Due to the MW adsorption by the cross-linked $\beta$-CD framework, further agglomeration of the $\mathrm{Pd}$ nanoparticles occurred when increasing the MW power at $200^{\circ} \mathrm{C}$, as shown in Figure $3 \mathbf{b}$. Indeed, the mean diameter of the $\mathrm{Pd}$ nanoparticles increased up to $10.0 \pm 4.1 \mathrm{~nm}$ (Figure 3c), which negatively affected the $\mathrm{Pd} / \mathrm{C} \beta \mathrm{CAT}$ stability. In addition, on the stressed catalyst the presence of peaks related to residual unreacted adsorbed species was detected by EDS analysis (Figure S5).

\section{CONCLUSIONS}

In this work, we have developed a sustainable protocol for the direct arylation of thiophenes using a heterogeneous Pd catalyst and a green solvent, GVL, which is suited for use in MWassisted reactions. This process takes advantage of the cooperative effect between MWs and Pd/C $\beta C A T$, since the reaction does

\section{REFERENCES}

Ackermann, L., Vicente, R., and Kapdi, A. R. (2009). Übergangsmetallkatalysierte direkte Arylierungen von (Hetero)Arenen durch C-H-Bindungsbruch. Angew. Chem. 121, 9976-10011. doi: 10.1002/ange.200902996

Calcio Gaudino, E., Carnaroglio, D., Martina, K., Palmisano, G., Penoni, A., and Cravotto, G. (2015). Highly efficient microwave-assisted CO aminocarbonylation with a recyclable Pd(II)/TPP- $\beta$-cyclodextrin cross-linked catalyst. Org. Process Res. Dev. 19, 499-505. doi: 10.1021/op5003374

Calcio Gaudino, E., Tagliapietra, S., Palmisano, G., Martina, K., Carnaroglio, D., and Cravotto, G. (2017). Microwave-assisted, green synthesis of 4(3H)quinazolinones under $\mathrm{CO}$ pressure in $\gamma$-valerolactone and reusable $\mathrm{Pd} / \beta$ cyclodextrin cross-linked catalyst. ACS Sust. Chem. Eng. 5,9233-9243. doi: 10.1021/acssuschemeng.7b02193 not proceed at all under traditional heating using the same catalyst and conditions. MW irradiation led to the formation of catalytically active $\mathrm{Pd}$ nanoparticles that are stabilized by the polymeric network. These findings were then applied to an atom-economical methodology that yielded a fluorescent quinazolinone derivative. The developed protocol is simple and cheap, avoids tedious workup procedures and works efficiently under MW irradiation. The robust heterogeneous Pd catalyst showed limited metal leaching (1.04\%) in GVL. The generation of bioactive heterocycles in a multistep one-pot process avoids the need to isolate intermediates and perform purification steps making it unbeatable in terms of costs and waste reduction, and thus an efficient and sustainable process.

\section{DATA AVAILABILITY STATEMENT}

All datasets generated for this study are included in the article/Supplementary Material.

\section{AUTHOR CONTRIBUTIONS}

ST and EC: methodology experimental design. EA, ST, and EC: investigation. ST and MM: data curation. MM and BB: catalyst analysis. ST and EC: original draft preparation. GC: review and editing.

\section{FUNDING}

This research was funded by the University of Turin (Ricerca locale 2018).

\section{ACKNOWLEDGMENTS}

The authors were grateful to Dr. Giorgio Volpi for his work on the fluorescence properties of the quinazolinone derivative.

\section{SUPPLEMENTARY MATERIAL}

The Supplementary Material for this article can be found online at: https://www.frontiersin.org/articles/10.3389/fchem. 2020.00253/full\#supplementary-material

Cano, R., Schmidt, A. F., and McGlacken, G. P. (2015). Direct arylation and heterogeneous catalysis; ever the twain shall meet. Chem. Sci. 6, 5338-5346. doi: 10.1039/C5SC01534K

Cao, S. L., Feng, Y. P., Jiang, Y. Y., Liu, S. Y., Ding, G. Y., and Li, R. T. (2005). Synthesis and in vitro antitumor activity of 4(3H)-quinazolinone derivatives with dithiocarbamate side chains. Bioorg. Med. Chem. Lett. 15, 1915-1917. doi: 10.1016/j.bmcl.2005. 01.083

Cho, H., Schäfer, C., and Török, B. (2016). "Microwave assisted solid acid catalysis," in Microwaves in Catalysis-Fundamental Research and Scale-up Technology, eds S. Horikoshi and N. Serpone (Weinheim: Wiley-VCH), 193. doi: 10.1002/9783527688111.ch10

Cintas, P., Cravotto, G., Gaudino, E., Orio, L., and Boffa, L. (2012). Reticulated $\mathrm{Pd}(\mathrm{II}) / \mathrm{Cu}(\mathrm{I})$ cyclodextrin complexes as recyclable green 
catalyst for sonogashira alkynylation. Catal. Sci. Technol. 2, 85-87. doi: 10.1039/C1CY00378J

Clarke, C. J., Tu, W.C., Levers, O., Bröhl, A., and Hallett, J. P. (2018). Green and sustainable solvents in chemical processes. Chem. Rev. 118, 747-800. doi: 10.1021/acs.chemrev.7b00571

Connors, K. A. (1997). The stability of cyclodextrin complexes in solution. Chem. Rev. 975, 1325-1358. doi: 10.1021/cr960371r

Crabtree, R. H., and Lei, A. (2017). Introduction: CH activation. Chem. Rev. 117, 8787-8863. doi: 10.1021/acs.chemrev.7b00307

Cravotto, G., Calcio Gaudino, E., Tagliapietra, S., Carnaroglio, D., and Procopio, A. (2012). A green approach to heterogeneous catalysis using ligand-free, metal-loaded cross-linked cyclodextrins. Green Process. Synth. 1, 269-273. doi: 10.1515/gps-2012-0029

Cravotto, G., and Carnaroglio, D. (2017). Microwave Chemistry. Berlin; Boston, MA: De Gruyte.

Das, S., Banik, R., Kumar, B., Roy, S., Amhad, K., and Sukul P. K. (2019). A green approach for organic transformations using microwave reactor. Curr. Org. Synth. 16, 730-764. doi: 10.2174/15701794166661904121 60048

Daştan, A., Kulkarni, A., and Török, B. (2012). Environmentally benign synthesis of heterocyclic compounds by combined microwave-assisted heterogeneous catalytic approaches. Green Chem. 14, 17-37. doi: 10.1039/C1GC $15837 \mathrm{~F}$

De la Hoz, A., and Loupy, A. (2012). Microwaves in Organic Synthesis. Weinheim: Wiley-VCH.

Fischmeister, C., and Doucet, H. (2011). Greener solvents for ruthenium and palladium-catalyzed aromatic C-H bond functionalisation. Green Chem. 13, 741-753. doi: 10.1039/c0gc00885k

Gandeepan, P., Kaplaneris, N., Santoro, S., Vaccaro, L., and Ackermann, L. (2019). Biomass-derived solvents for sustainable transition metalcatalyzed C-H activation. ACS Sust. Chem. Eng. 7, 8023-8040. doi: 10.1021/acssuschemeng.9b00226

Gutmann, B., Cantillo, D., and Kappe, C. O. (2015). Continuous-flow technologya tool for the safe manufacturing of active pharmaceutical ingredients. Angew. Chem. Int. Ed. 54, 6688-6728. doi: 10.1002/anie.201409318

Hapiot, F., Bricout, H., Menuel, S., Tilloy, S., and Monflier, E. (2014). Recent breakthroughs in aqueous cyclodextrin-assisted supramolecular catalysis. Catal. Sci. Technol. 4, 1899-1908. doi: 10.1039/c4cy00005f

Jimenez-Gonzalez, C., Ponder, C. S., Broxterman, Q. B., and Manley, J. B. (2011). Using the right green yardstick: why process mass intensity is used in the pharmaceutical industry to drive more sustainable processes. Org. Process Res. Dev. 15, 912-917. doi: 10.1021/op200097d

Kappe, C. O. (2004). Controlled microwave heating in modern organic synthesis. Angew. Chem. Int. Ed. 43, 6250-6284. doi: 10.1002/anie.2004 00655

Khan, I., Zaib, S., Batool, S., Abbas, N., Ashraf, Z., Iqbal, J., et al. (2016). Quinazolines and quinazolinones as ubiquitous structural fragments in medicinal chemistry: an update on the development of synthetic methods and pharmacological diversification. Bioorg. Med. Chem. 24, 2361-2381. doi: 10.1016/j.bmc.2016.03.031

Kitanosono, T., Masuda, K., Xu, P., and Kobayashi, S. (2018). Catalytic organic reactions in water toward sustainable society. Chem. Rev. 118, 679-746. doi: 10.1021/acs.chemrev.7b00417

Kokel, A., Schäfer, C., and Török, B. (2017). Application of microwave-assisted heterogeneous catalysis in sustainable synthesis design. Green Chem. 19, 3729-3751. doi: 10.1039/C7GC01393K

Lafrance, M., and Fagnou, K. (2006). Palladium-catalyzed benzene arylation: incorporation of catalytic pivalic acid as a proton shuttle and a key element in catalyst design. J. Am. Chem. Soc. 128, 16496-16497. doi: 10.1021/ja0 $67144 \mathrm{j}$

Martins, M. A. P., Frizzo, C. P., Moreira, D. N., Buriol, L., and Machado, P. (2009). Solvent-free heterocyclic synthesis. Chem. Rev. 109, 4140-4182. doi: $10.1021 / \mathrm{cr} 9001098$

Masui, K., Mori, A., Okano, K., Takamura, K., Kinoshita, M., and Ikeda, T. (2004). Syntheses and properties of donor-acceptor-type 2,5-diarylthiophene and 2,5-diarylthiazole. Org. Lett. 6, 2011-2014. doi: 10.1021/ol04 $9386 z$
Meyer, T. H., Finger, L. H., Gandeepan, P., and Ackermann, L. (2019) Resource economy by metallaelectrocatalysis: merging electrochemistry and C-H activation. Trends Chem. 1, 63-76. doi: 10.1016/j.trechm.2019. 01.011

Moseley, J. D., and Kappe, C. O. (2011). A critical assessment of the greenness and energy efficiency of microwave-assisted organic synthesis. Green Chem. 13, 794-806. doi: $10.1039 / \mathrm{c} 0 \mathrm{gc} 00823 \mathrm{k}$

Orduna, J. S., Mudarra, Á. L., Martínez de Salinas, S., and Pérez-Temprano, M. H. (2019). Sustainable knowledge-driven approaches in transition-metal-catalyzed transformations. ChemSusChem. 12, 2882-2897. doi: 10.1002/cssc.2019 00914

Petricci, E., Risi, C., Ferlin, F., Lanari, D., and Vaccaro, L. (2018). Avoiding hot-spots in microwave assisted $\mathrm{Pd} / \mathrm{C}$ catalyzed reactions by using the biomass derived solvent $\gamma$-Valerolactone. Sci. Rep. 8, 10571-10581. doi: 10.1038/s41598-018-28458-y

Polshettiwar, V., Nadagouda, M. N., and Varma, R. S. (2009). Microwaveassisted chemistry: a rapid and sustainable route to synthesis of organics and nanomaterials. Aust. J. Chem. 62, 16-26. doi: 10.1071/CH0 8404

Polshettiwar, V., and Varma, R. S. (2008). Microwave-assisted organic synthesis and transformations using benign reaction media. Acc. Chem. Res. 41, 629-639. doi: $10.1021 /$ ar700238s

Rao, R. G., Blume, R., Hansen, T. W., Fuentes, E., Dreyer, K., Moldovan, S., et al. (2017). Interfacial charge distributions in carbon-supported palladium catalysts. Nat. Commun. 8:340. doi: 10.1038/s41467-017-00421-x

Rasina, D., Kahler-Quesada, A., Ziarelli, S., Warratz, S., Cao, H., Santoro, S., et al. (2016). Heterogeneous palladium-catalyzed catellani reaction in biomass-derived $\gamma$-valerolactone. Green Chem. 18, 5025-5030. doi: 10.1039/C6GC01393G

Rasmussen, S. C. J., Evenson, S. J., and McCausland, C. B. (2015). Fluorescent thiophene-based materials and their outlook for emissive applications. Chem. Commun. 51, 4528-4542. doi: 10.1039/C4CC09206F

Roger, J., PoŽgan, F., and Doucet, H. (2009). Ligand-less palladium-catalyzed direct 5-arylation of thiophenes at low catalyst loadings. Green Chem. 11, 425-432. doi: 10.1039/b819912d

Santoro, S., Kozhushkov, S. I., Ackermann, L., and Vaccaro, L. (2016). Heterogeneous catalytic approaches in $\mathrm{C}-\mathrm{H}$ activation reactions. Green Chem. 18, 3471-3493. doi: 10.1039/C6GC00385K

Santoro, S., Marrocchi, A., Lanari, D., Ackermann, L., and Vaccaro, L. (2018). Towards sustainable $\mathrm{C}-\mathrm{H}$ functionalization reactions: the emerging role of bio-based reaction media. Chem. Eur. J. 24, 13383-13390. doi: $10.1002 /$ chem.201801114

Sharma, N., Bahadur, V., Sharma, U. K., Saha, D., Li, Z., Kumar, Y., et al. (2018). Microwave-assisted ruthenium-catalyzed ortho- $\mathrm{C}-\mathrm{H}$ functionalization of N-benzoyl $\alpha$-amino ester derivatives. Adv. Synth. Catal. 360, 3083-3089. doi: 10.1002/adsc.201800458

Sheldon, R. A. (2012). Fundamentals of green chemistry: efficiency in reaction design. Chem. Soc. Rev. 41, 1437-1451. doi: 10.1039/C1CS15219J

Tabasso, S., Calcio Gaudino, E., Acciardo, E., Manzoli, M., Giacomino, A., and Cravotto, G. (2019). Microwave-assisted dehydrogenative cross coupling reactions in $\gamma$-valerolactone with a reusable $\mathrm{Pd}$ - cyclodextrin crosslinked catalyst. Molecules 24, 288-301. doi: 10.3390/molecules24 020288

Tabasso, S., Calcio Gaudino, E., Rinaldi, L., Ledoux, A., Larini, P., and Cravotto, G. (2017). Microwave-assisted, ligand-free, direct C-H arylation of thiophenes in biomass-derived $\gamma$-valerolactone. New J. Chem. 41, 9210-9215. doi: $10.1039 / C 7 N J 01540 B$

Tabasso, S., Grillo, G., Carnaroglio, D., Calcio Gaudino, E., and Cravotto, G. (2016). Microwave-assisted $\gamma$-valerolactone production for biomass lignin extraction: a cascade protocol. Molecules 21, 413-421. doi: 10.3390/molecules 21040413

Tee, O. S., Gadosy, T. A., and Giorgi, J. B. (1996). Dissociation constants of host-guest complexes of alkyl-bearing compounds with $\beta$-cyclodextrin and "hydroxypropyl- $\beta$-cyclodextrin". Can. J. Chem. 74, 736-744. doi: $10.1139 / \mathrm{v} 96-080$

Tian, X., Yang, F., Rasina, D., Bauer, M., Warratz, S., Ferlin, F., et al. (2016). C-H arylations of 1,2,3-triazoles by reusable heterogeneous palladium 
catalysts in biomass-derived $\gamma$-valerolactone. Chem. Commun. 52, 9777-9780. doi: 10.1039/C6CC03468C

Turner, G. L., Morris, J. A., and Greaney, M. F. (2007). Direct arylation of thiazoles on water. Angew. Chem. Int. Ed. 46, 7996-8000. doi: 10.1002/anie.200702141

Voogt, E. H., Mens, A. J. M., Gijzeman, O. L. J., and Geus, J. W. (1996). XPS analysis of palladium oxide layers and particles. Surf. Sci. 350, 21-31. doi: 10.1016/0039-6028(96)01028-X

Warratz, S., Burns, D. J., Zhu, C., Korvorapun, K., Rogge, T., Scholz, J., et al. (2017). Meta-C-H bromination on purine bases by heterogeneous ruthenium catalysis. Angew. Chem. Int. Ed. 56, 1557-1560. doi: 10.1002/anie.2016 09014
Conflict of Interest: The authors declare that the research was conducted in the absence of any commercial or financial relationships that could be construed as a potential conflict of interest.

Copyright (c) 2020 Tabasso, Calcio Gaudino, Acciardo, Manzoli, Bonelli and Cravotto. This is an open-access article distributed under the terms of the Creative Commons Attribution License (CC BY). The use, distribution or reproduction in other forums is permitted, provided the original author(s) and the copyright owner(s) are credited and that the original publication in this journal is cited, in accordance with accepted academic practice. No use, distribution or reproduction is permitted which does not comply with these terms. 